\title{
Enhancing students' employability skills and experiential learning through integration of Xero software
}

\author{
Greg Jones, Hazel Jones, Dom Pensiero, Claire Beattie \\ University of Southern Queensland, Griffith University, University of Southern Queensland, Lincoln University
}

\begin{abstract}
Introducing XERO Accounting software into a core accounting unit can have many benefits for students, including improving their professional skills and enhancing their employability. However, it is important that students gain knowledge and skills in all aspects of the software as well as understanding the accounting processes that underlie the software's operations. This paper presents an overview of implementation of Xero software, in a core accounting course, at a regional university in Australia. Student numbers ranged from 24-63 across the semesters studied. We highlight and discuss the processes adopted to appropriately scaffold students' learning and assessment. We assess the effectiveness of the intervention by observing student engagement with specially developed videos and measuring student results in associated assessment tasks over three offerings of the course. The provision of a suite of learning opportunities, (training and use of excel and Xero accounting software) translated to improved student outcomes on the technologyrelated assessment items. Few students who viewed the learning videos contacted the course teaching team for further assistance, suggesting the videos were an effective resource that provided enhanced learning opportunities for students. These findings provide advice and information regarding the issues associated with integrating accounting software for other teaching teams or institutions considering similar applications in their courses or programs. Keywords: Accounting software (Xero), employability, experiential learning, I Framework
\end{abstract}

\section{Introduction and Background}

The use of accounting software in accounting programs is an essential requirement of the external accreditation of accounting programs by the professional accounting bodies (CPA and CAANZ). This can be achieved through a stand-alone information systems course or embedded technology throughout the accounting program. At the case site, there was an information systems course designed to meet these requirements. However, the decision was made to discontinue this course and embed accounting software in the first course in the accounting major. There are multiple accounting programs capable of being used to teach and perform accounting functions. Excel is widely used within the profession and having at least a fundamental knowledge of its functions and capabilities is an essential building block in developing knowledge of more advanced accounting software skills and knowledge. Xero (https://www.xero.com/) is a commonly used accounting software package designed for small businesses and was chosen for use in this course due to its wide applicability. In addition, students were able to complete a Xero Advisor Certificate through voluntary completion of a series of Xero modules as a co-curricular activity.

This study was conducted in the first accounting course in the accounting major and a prerequisite for the following accounting courses. It introduces fundamental accounting concepts and basic accounting transactions. The structure of the course means that students initially prepare manual transactions. Once they have mastered this process their learning is scaffolded through using Excel and Xero accounting software to process similar accounting transactions. To support the students' learning journey the course team developed a series of instructional videos. These were supplemented with training material from Xero Learn. Videos were chosen as the format for this support due to their reported benefits (Holtzblatta, \& Tschakert, 2011), especially for students learning in an online or hybrid environment. The benefits of using instructional videos in a range of disciplines include improved student experience and engagement, increased cognitive and procedural knowledge, high student satisfaction with teaching experience, greater confidence and motivation and lower anxiety levels (D’Aquila et al., 2019; Forbes et al., 2016). Students also benefit from the convenience of accessing videos at a 
time that suits them as well as the capacity to return to the videos to refresh previously covered material (Holtzblatta \& Tschakert, 2011).

\section{Literature Review}

The role of accountants in today's business world has been affected by the context in which they operate, the influence of changes in technology on data collection and analysis, and the summarisation and disaggregation of data for reporting (Wells, 2018). Industry and professional bodies all value, and indeed require accounting graduates to have ICT skills, specifically the ability to apply accounting information systems to a range of work contexts. Integration of accounting software applications is thus an important consideration across accounting programs. Such integration has been shown to enrich students' education through experiential learning that improves their accounting competencies which enhances their employability (Alshurafat et al., 2020; Machera \& Machera, 2017). Professional bodies such as the Association of Chartered Certified Accountants (ACCA) have identified that accountants are required to work across a diffuse range of contexts and that digitalisation (and technology) is revolutionising work in the profession with graduates needing to have knowledge of this nexus of work and technology (ACCA, 2016; Lyon, 2020). Similarly, Viviers and de Villiers (2020) propose that the infiltration of data analysis and technology into business decision making processes has resulted in changes in the nature of today's work processes which requires practitioners to be able to navigate through the technology and use it effectively. In Australia the accrediting bodies have now recognised the growing technological demands in the accounting profession and have mandated that software must be taught to undergraduate accounting students intending to join one of the professional bodies.

Experiential learning is one approach to providing opportunities for students to gain these important skillsets. In this paper we have adopted a revision to Kolb's experiential learning: "experiential learning consists of contextually rich concrete experience, critical reflective observation, contextual-specific abstract conceptualization, and pragmatic active experimentation." (Morris, 2020, p.1064). The effectiveness of experiential learning opportunities can be measured through determination of student engagement with those opportunities. Student engagement has been defined in many ways over the past century (Groccia, 2018) and for this project we chose the definition from Kuh (2009, p.683) i.e., "the time and effort students devote to activities that are empirically linked to desired outcomes of college and what institutions do to induce students to participate in these activities. This definition is closely aligned with our approach of encouraging experiential learning and allowing students to develop learning through performing multiple transactions to enhance confidence. Measurement of student engagement is one aspect of learning analytics (LA), "[t]he measurement, collection, analysis and reporting of data about learners and their contexts, for purposes of understanding and optimising learning and the environments in which it occurs" (LAK11, 2011, para 5). LA have gained momentum over the last decade as an efficient and effective method for measuring impact of teaching interventions and informing course design (Lockyer et al., 2013). Whilst early LA frameworks and approaches focussed on technological and data processing aspects of LA use (Siemens, 2013), most models have included stakeholders and the need to take action as a result of insights gained from student data (Dyckhoff et al., 2011; Greller \& Drachsler, 2012). More recent frameworks have had strong links to Learning Design (LD), showing ways LA can both measure and inform LD and how LD impacts on the most effective data to interrogate (Bakharia et al., 2016; Gunn et al., 2017). In this study we chose to adopt the I framework (Jones, 2015) as this offered a practical approach relevant for implementation at an individual course level, whereas many of the other frameworks have a more theoretical and/or institutional focus.

\section{Phased Intervention}

The primary question being addressed in this study was to determine the impact of different teaching and support strategies in assisting students to develop accounting technology knowledge and skills essential within the accounting program and workplace. We were interested in this because accreditation requirements from the professional bodies incorporate teaching, practicing, and assessing the use of accounting software, and the desire to provide enhanced skills and knowledge which would lead to improved employability prospects.

\section{Phase 1}

The first phase of the teaching processes introduced students to recording transactions. These were initially manually taught and practiced, and then taught, practiced, and assessed using Excel. The purpose of this approach was to scaffold students' learning, allowing them to develop an understanding of the basic concepts and then to facilitate and develop the skills needed in practice through the use and application of accounting 
processes in Excel. This was designed to build competence and confidence in understanding discipline knowledge and basic accounting concepts. Through a process of recording the journal entries, debits, and credits, and then following the information flow process to create the financial reports. This provided the opportunity to enhance understanding of the workflow related to financial report generation.

The Excel task was used to teach and reinforce these foundation accounting concepts. Students were given a trial balance ending in May, and then were required to perform accounting transactions for June, make the adjusting entries and then link through to the T-accounts and then to the financial statements. This process was designed to encourage students to initially learn how to do the transactions manually and then, using Excel, to develop an understanding of how the transactions flowed through the accounting process to the financial reports. Similarly, the adjusting entries required linking through to the financial reports. This allowed students to further conceptualise the flow of accounting information and visualise how accounting transactions, and adjustments, impacted on the various final financial reports.

\section{Phase 2}

In line with professional bodies accreditation requirements the second phase of this teaching involved using a specialised accounting software. After exploring several accounting software applications, the accounting discipline group (composed of teaching academics) decided to adopt Xero. This program is cloud based so students did not need to have the program installed on their computer and could access the cloud-based program through the University licence. As the first part of the course had provided students with the opportunity to develop their foundational knowledge and skills, Xero was used to develop that knowledge in a very practical way. Students were required to complete the transactions and produce financial reports. After the initial semester of using this software, it was apparent that students struggled to accurately process transactions in the software. Additionally, the University was afforded the opportunity to work with this industry partner and to offer the Xero Advisor Certification for students undertaking a course using the software. This certificate, run by Xero, consists of 12 modules, is industry recognised, used by $80 \%$ of SMEs and enhances students' employability. However, the course team noted that this certificate was targeted to people already working in the industry, who had support from their workplaces to develop their skills and were seeking to advance their knowledge and professional recognition. A substantial proportion of the students enrolled in this course were not working in the industry and had no professional experience. Using this software was new to them therefore there was a need to teach both, the technical aspects related to performing accounting transactions, as well as how to use the software to achieve the desired results.

Considering the dual benefits students could gain from learning how to use Xero, consideration was given to how best to achieve those goals. The Xero Advisor Certificate was supported, via online modules hosted by the industry partner. However, these resources were targeted at students who had a moderate level of practical experience. The student cohort did not possess this base knowledge, so the decision was made to provide additional training to assist them in completing the industry Xero training modules. We wanted to avoid creating a step-by-step approach and decided to create recordings which would enhance learning rather than something that would simply demonstrate what to do. The decision was made to create short videos to assist students with developing accounting skills rather than it being a rote transactional process, thus deepening their learning and knowledge. First, one of the teaching team first completed the certificate training module. Then, in conjunction with the remainder of the team, they discussed and identified where students may encounter issues. Recordings were then developed for each module, identifying these potential issues, and provided guidance to address them. Students were advised that completion of the advisor certificate was voluntary and not assessed, however, they were also informed that completion of specified modules would assist them in the completion of their assignment. Completion of these modules enhanced students' abilities, knowledge and skills for future courses and in the workplace.

The related assignment did not encompass all Xero functionalities, so the videos initially focussed on modules relevant to the course and assignment task. Workshop recordings were also made to assist students through the types of tasks they would need to complete to address the assessment piece. Additional zoom sessions were conducted to enable students not on campus to directly interact with teaching staff. Access to the Xero advisor course was kept open for a period of the two weeks after the exam period to allow students to complete any of the non-essential modules they had not attempted previously and complete the certificate as desired. 


\section{Practical Approach}

Students in this course were able to enrol either face-to-face or fully online. The impact of COVID-19 was that even some face-to-face students were at times forced to participate in the online mode. The blend of face to face and online students necessitated a broad range of interventions to ensure accessibility for all students. Additional workshops, both face to face and online using Xero were introduced and recordings made available. Tutorial questions used Xero to allow students, with guidance and instruction, to practise accounting transactions within the accounting software. Other problems were also identified, and additional support was provided to address these. There were several terminology issues which needed to be addressed for students to understand the program. The language of accounting is specific, but language adopted by the software was simplified to allow personnel in SMEs and business with little accounting knowledge to use the software. To address this issue, workshops and presentations were used to explain links between these different terminologies. For example, normal accounting terminology for money owed to a supplier would be 'account payable', however within Xero this type of transaction was referred to as 'money owed'.

\section{Evaluation}

Students in this study were fully informed of the research project and ethical clearance was obtained (USQ ethical approval number H20REA077). As noted above, this study followed the I framework to evaluate the effectiveness of the integration of Xero.

Looking at how each step of the framework was applied in this study we note:

- Institutional context: This was the first course in the accounting major of a Bachelor of Business and Commerce program in a regional Australian university where there is a mix of fully online and hybrid learning. This course was a prerequisite for the following accounting courses. As a result of COVID-19 face-to-face classes were replaced with online learning on multiple occasions.

Impetus: The question this study aimed to address was the extent to which the integration of Xero software into a core accounting course could enhance students' learning and improve engagement with course material.

- Input: A range of baseline data was gathered to inform the intervention, including results and feedback from students. This data was obtained from the first offering of the course where there had been support provided through workshops and online sessions, but there were no video recordings showing 'how to' perform and manage the Xero software. Analysis of progression data also suggested that students found this course challenging to complete and it was evident that some students struggled to meet the learning outcomes in relation to the accounting software assessment items.

- Intervention: In the phased intervention (Phase 2) the project team supported the introduction to Xero software through a series of instructional videos that explained the various accounting processes. These were designed to step students through a variety of business transactions and show them the correct way to process the data through Xero.

- Impact: The effectiveness of the intervention was assessed using a range of data including:

1. Student views of each video.

2. Student grades in the Xero assignment.

3. Qualitative data including student emails and feedback from teaching staff.

4. Student responses in feedback survey

5. Interaction data with the Learning Management System (LMS)

This paper focuses on the first two of these data sources.

\section{Results}

The data for this study comprised 199 students enrolled in this course over four teaching periods. The first offering, Semester 12020 (TP 1), $\mathrm{n}=68$ is provided as baseline data for some of the following data, as this was the last offering before the Xero training modules were offered. Prior to the introduction of the Xero training modules the assessments had the same requirements and online and face-to-face Xero training sessions were provided. Invalid or incomplete entries as well as entries where students had not completed the assessment items for the course were removed from the analysis leaving a final sample size of 125. 
Students' engagement with the relevant instructional videos were recorded for three teaching periods from S2 2020, S3 2020 and S1 2021 in the first accounting course in the major. Students were able to access each video as many times as they desired. Table 1 shows the number of students who accessed the video, the number of times the video was accessed (frequency) and the range of access for each video. The three teaching periods can be summarised as follows:

- Semester 22020 - First deployment of Xero teaching and modules (TP 2), n= 63

- Semester 32020 - Second deployment of Xero teaching and modules (TP 3), n=24

- Semester 12021 - Third deployment of Xero teaching and modules (TP 4), n= 44

The low numbers in TP 3 are to be expected as this is the teaching period for Semester 3, the so called 'summer semester' which students traditionally use to 'catch up' if they have previously failed a course or had not completed their studies during the 'normal' Semester 1 and Semester 2 teaching periods.

Whilst all modules contributed to the official Advisor Certification, only the five modules included in Table 1 related to the types of actions students were required to perform in the Xero assignment.

Table 1. Xero Module Usage for modules associated with the major assignment

\begin{tabular}{|l|c|c|c|c|c|c|c|c|c|}
\hline & \multicolumn{3}{|c|}{ Semester 2 2020 } & \multicolumn{3}{c|}{ Semester 3 2020 } & \multicolumn{3}{c|}{ Semester 1 2021 } \\
\cline { 2 - 10 } & Freq & Students & Range & Freq & Students & Range & Freq & Students & $\begin{array}{c}\text { Rang } \\
\text { e }\end{array}$ \\
\hline Invoice settings & 8 & 5 & 1 to 4 & 22 & 14 & 1 to 3 & 65 & 28 & 1 to 6 \\
Create \& adjust & 23 & 14 & 1 to 3 & 28 & 16 & 1 to 3 & 37 & 21 & 1 to 3 \\
Create Bills & 13 & 13 & 1 to 1 & 21 & 13 & 1 to 3 & 36 & 21 & 1 to 4 \\
Adv Tools-Journals & 16 & 10 & 1 to 3 & 27 & 15 & 1 to 4 & 39 & 20 & 1 to 4 \\
Customised Reports & 10 & 5 & 1 to 3 & 17 & 10 & 1 to 3 & 25 & 16 & 1 to 3 \\
\hline
\end{tabular}

The proportion of students accessing these recordings has steadily increased, partly through the teaching team promoting the use of them to students, and partly through a process of making them more visible and prominent on the study desk.

\section{Descriptive Statistics}

Discussed are the contribution of the modules on students' performance in the Xero assignment and their overall final grades.

Figure 1. Mean grades in assignments 2, 3 and exam.

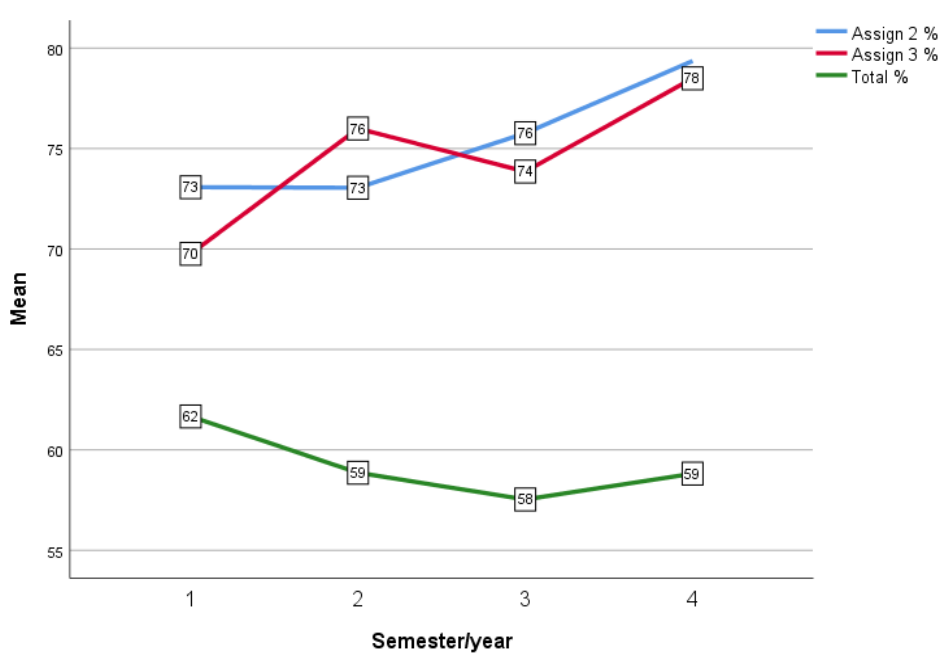


Figure 1 shows the progression of mean scores (in percentages) in both the second assignment, and the Xero assignment (Assignment 3) and the overall performance of the students. Assignment 1 is not included in our analysis as this was a low stakes summative assessment piece designed to support students in engaging with the course and receiving feedback before submitting the subsequent assessment items. Further, exam scores were not included as the exam did not assess Xero or any of its modules as students were subject to normal exam conditions and access to computers/software etc. was not permitted. Figure 1 shows that the performance in both assessment pieces (assignment 2 and 3) have increased overall over the 4 teaching periods although there was a drop in the performance of assignment 3 between teaching periods 2 and 3.

This is expected as many students in this teaching period 3 (the 'summer semester') have previously struggled with the course material and were repeating the course. The total performance line shows a drop in overall performance between teaching periods 1 to 3 but a slight increase in teaching period 4 to be consistent with teaching period 2. This is attributable to two main factors; namely, that the final grades are heavily weighted by the final exam and there appears to have been a lag effect from the introduction of Xero to the overall final performance in teaching period 4. Further data is required to confirm whether this overall shift in the overall performance has continued.

When examining the Xero modules overall, of notable interest was the module 'Workshop - How to record Transactions' as this module combined many of the components of previous modules, perhaps contributing to the difficulty of isolating the individual effect of each module as explained later in our analysis section. At this juncture we present a simple overview of the workshop module given that it is a composite module, covering a variety of Xero transactions, and student assignment results are shown in Figure 2. The distribution of the number of times students accessed the workshop module ranged from 0 to 24 with $83.2 \%$ accessing the Workshop module between 1 and 7 times. As shown in Figure 2, the mean performance of the major Xero assignment was consistently between $73 \%$ to $80 \%$ when students accessed the workshop up to 12 times. This suggests that the cumulative effect of a progressive suite of Xero instructive modules has resulted in a consistent and reasonably high performance in the major Xero assessment.

Deeper analysis showed that high multiple views of the same recording were either from students who are having difficulties with the content (subsequent lower than average mark in the assignment), or high performing students wanting to achieve near perfect marks. Very few students, after viewing the workshop video, came back to the teaching team for further assistance. This suggested that students recognised and used the Xero resources, which had been created to empower students to self-manage their study. Correspondence related to this resource with students via email and the course LMS was all positive.

Figure 2. Mean performance of Xero assessment by number of times Workshop module accessed. $(\mathbf{n}=125)$

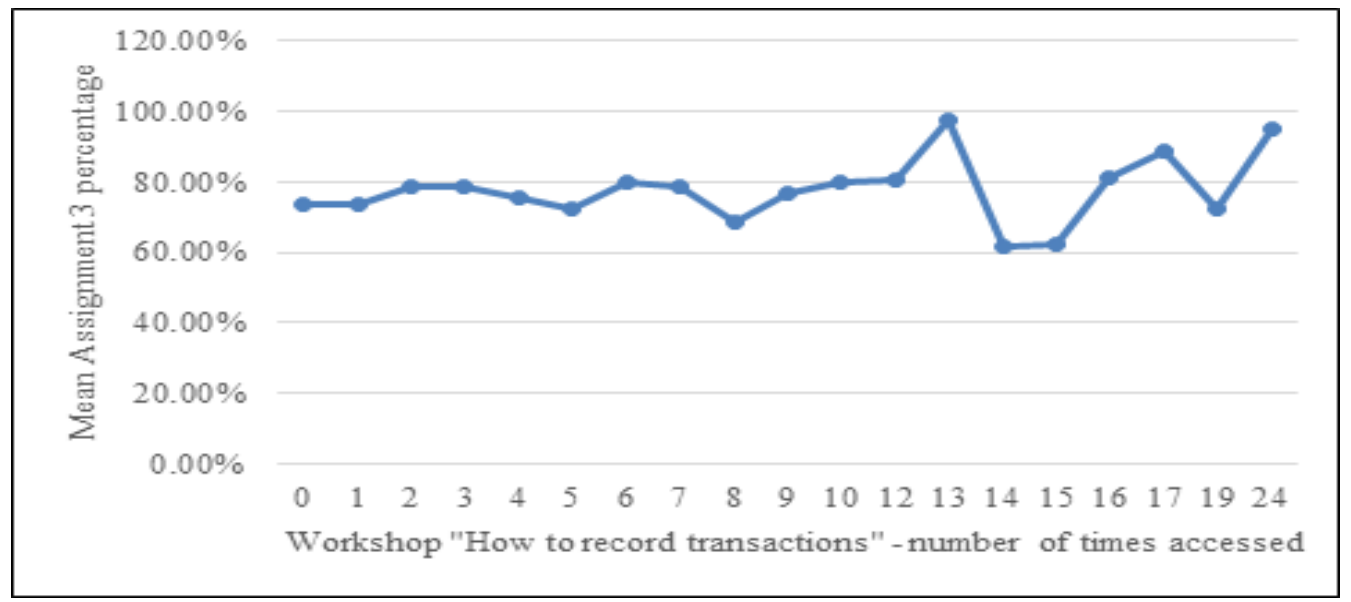

Only six students did not access the workshop and further investigation revealed all six students had previous exposure to Xero in their work environments and therefore had felt no need to access the workshop module. These six students performed well in their assignments and in communication with the teaching team explained that as they were using the software in their workplace, they saw no reason to further engage with the training. 
When students accessed the workshop module more than 12 times (i.e., between 13 and 24 times) the mean assignment performance varied markedly from $61 \%$ to $98 \%$. These apparently variable responses could, however, be the product of small sample sizes as in all cases only 1 or 2 students were involved.

\section{Correlations}

As we were interested in the influence that the Xero based major assessment had on student performance, correlation analysis allowed us a first look at the association between the assignments and students final grade. The results are reported in Table 2 below which show that correlations between assessment items 2, 3 and overall performance all have a significant positive association.

Table 2. Correlations between assessment items

\begin{tabular}{|ll|r|r|r} 
& & Assign 2\% & Assign 3\% & \multicolumn{1}{c}{ Total \% } \\
\hline Assign 2\% & Pearson Correlation & 1 & $.557^{\star \star}$ & \multicolumn{1}{c}{$.635^{\star \star}$} \\
\cline { 2 - 5 } & Sig. (2-tailed) & & .000 & .000 \\
\cline { 2 - 5 } & $\mathrm{N}$ & 199 & 199 & 199 \\
\hline \multirow{2}{*}{ Assign 3\% } & Pearson Correlation & $.557^{\star \star}$ & 1 & $.677^{\star \star}$ \\
\cline { 2 - 5 } & Sig. (2-tailed) & .000 & & .000 \\
\cline { 2 - 5 } & $\mathrm{N}$ & 199 & 200 & 200 \\
\hline \multirow{2}{*}{ Total \% } & Pearson Correlation & $.635^{\star \star}$ & $.677^{\star \star}$ & 1 \\
\cline { 2 - 5 } & Sig. (2-tailed) & .000 & .000 & \\
\cline { 2 - 5 } & $\mathrm{N}$ & 199 & 200 & 200 \\
\hline
\end{tabular}

**. Correlation is significant at the 0.01 level (2-tailed).

As we are interested in the impact of the Xero modules on assessment performance, correlations between the five identified Xero modules and assignment 3 are shown in Table 3 below. While all five modules are significantly positively correlated with each other, none of the five modules listed are individually shown to be significantly correlated with the major assignment suggesting that a cumulative effect, rather than that a specific module contributed to the final results.

Table 3. Correlations between five Xero modules and Assignment 3

\begin{tabular}{|c|c|c|c|c|c|c|c|}
\hline & & Assign $3 \%$ & $\begin{array}{l}\text { Invoice } \\
\text { settings }\end{array}$ & $\begin{array}{l}\text { Create and } \\
\text { adjust } \\
\text { invoices }\end{array}$ & Create Bills & $\begin{array}{l}\text { Advanced } \\
\text { Tools - } \\
\text { Journals }\end{array}$ & $\begin{array}{c}\text { Customised } \\
\text { Reports }\end{array}$ \\
\hline \multirow[t]{3}{*}{ Assign $3 \%$} & Pearson Correlation & 1 & .153 & 141 & .119 & .148 & .076 \\
\hline & Sig. (2-tailed) & & .196 & 207 & .292 & .197 & .522 \\
\hline & $\mathrm{N}$ & 200 & 73 & 82 & 81 & 78 & 73 \\
\hline \multirow[t]{3}{*}{ Invoice settings } & Pearson Correlation & .153 & 1 & $.618^{n \star}$ & $.511^{\star \star}$ & $.404^{* n}$ & $.504^{\times x}$ \\
\hline & Sig. (2-tailed) & .196 & & .000 & .000 & .001 & .000 \\
\hline & $\mathrm{N}$ & 73 & 73 & 71 & 70 & 70 & 70 \\
\hline \multirow{3}{*}{$\begin{array}{l}\text { Create and adjust } \\
\text { invoices }\end{array}$} & Pearson Correlation & .141 & $.618^{\mathrm{N}}$ & 1 & $.704^{* *}$ & $.643^{* \pi}$ & $.610^{* x}$ \\
\hline & Sig. (2-tailed) & .207 & .000 & & .000 & .000 & .000 \\
\hline & $\mathrm{N}$ & 82 & 71 & 82 & 75 & 74 & 71 \\
\hline \multirow[t]{3}{*}{ Create Bills } & Pearson Correlation & .119 & $.511^{\star \star}$ & $.704^{* *}$ & 1 & $.607^{\times \star}$ & $.544^{x x}$ \\
\hline & Sig. (2-tailed) & .292 & .000 & .000 & & .000 & .000 \\
\hline & $\mathrm{N}$ & 81 & 70 & 75 & 81 & 73 & 71 \\
\hline \multirow{3}{*}{$\begin{array}{l}\text { Advanced Tools - } \\
\text { Journals }\end{array}$} & Pearson Correlation & .148 & $.404^{n *}$ & $.643^{* *}$ & $.607^{* *}$ & 1 & $.708^{* *}$ \\
\hline & Sig. (2-tailed) & .197 & .001 & .000 & .000 & & .000 \\
\hline & $\mathrm{N}$ & 78 & 70 & 74 & 73 & 78 & 72 \\
\hline \multirow[t]{3}{*}{ Customised Reports } & Pearson Correlation & .076 & $.504^{n *}$ & $.610^{* *}$ & $.544^{* *}$ & $.708^{* *}$ & 1 \\
\hline & Sig. (2-tailed) & .522 & .000 & .000 & .000 & .000 & \\
\hline & $\mathrm{N}$ & 73 & 70 & 71 & 71 & 72 & 73 \\
\hline
\end{tabular}

\section{ANOVA Analysis}

An ANOVA analysis was conducted on the students' performance on their major Xero assignment (Assignment 3), their other assessment (Assignment 2 - non Xero), and their final grade to compare means across 4 teaching 
periods (the first, baseline course and the three subsequent periods). The results are shown in Table 4 below. All marks for assignments and final grades were converted to percentages whereas Xero modules were ordinal in nature ranging from 0 to 4 (teaching period 1) and 0 to 3 for teaching periods 2,3 and 4 .

\section{Table 4. ANOVA Analysis}

\begin{tabular}{lll|r|r|r|r} 
& & \multicolumn{1}{c}{$\begin{array}{c}\text { Sum of } \\
\text { Squares }\end{array}$} & df & Mean Square & \multicolumn{1}{c}{ F } & Sig. \\
\hline Assign 2\% & Between Groups & 1331.696 & 3 & 443.899 & .892 & .446 \\
\cline { 2 - 8 } & Within Groups & 97054.889 & 195 & 497.717 & & \\
\cline { 2 - 8 } & Total & 98386.585 & 198 & & & \\
\hline \multirow{2}{*}{ Assign 3\% } & Between Groups & 2294.881 & 3 & 764.960 & 2.959 & .033 \\
\cline { 2 - 8 } & Within Groups & 50665.049 & 196 & 258.495 & & \\
\cline { 2 - 8 } & Total & 52959.930 & 199 & & & \\
\hline Total \% & Between Groups & 420.313 & 3 & 140.104 & .587 & .624 \\
\cline { 2 - 8 } & Within Groups & 46764.916 & 196 & 238.597 & & \\
\cline { 2 - 8 } & Total & 47185.229 & 199 & & & \\
\hline
\end{tabular}

From Table 4, assignment 3 (Xero) was significantly different in means across the four teaching periods (significance level of 0.033 ).

When examining the modules that are believed to have contributed significantly to both the performance in the Xero assignment and the final performance, we ran a series of Kruskal Wallis tests using the five modules identified in Table 1 as the grouping variable in each case. Our results showed that none of the five modules were shown to significantly affect the performance in the Xero assignment. This could be because students could access each module an unlimited number of times or not at all. As such, we reran the analysis using a dummy variable with a value of 1 if the student had accessed the module at least once and a value of 0 if the student had not accessed the module at all. Our results using the Kruskall Wallis H test and using the 'dummy' five modules as our grouping variables confirmed that two of the five modules identified in Table 1 were significant in the performance of the major Xero assessment. These were the modules 'Create Bills' and 'Advanced Journals' (significance levels 0.015 and 0.007 respectively).

\section{Discussion}

The results from this study show that integration of Xero software and supporting video resources was effective in improving student outcomes in a technology-related assessment item. By developing accounting software skills, students were able to build foundation knowledge transferable within the profession. It is important for educators to consider the base knowledge of students as well as variation within the student cohort. Industry providers of technology tend to develop resources aimed at practising individuals. This means these cannot easily be embedded in an undergraduate course without sufficient supplementary materials. In this study it was important to provide opportunities for students to demonstrate both technical expertise and professional judgement when using the accounting software. The ability for students to develop transferable skills through their undergraduate study was supported by the teaching team's emphasis on problem solving and conceptual understanding of the accounting processes. This process demonstrated that there are significant benefits from partnering with industry specialists to enhance student employability. However, it is important that teaching teams work with the industry partner to develop relevant and appropriate learning opportunities.

\section{Further Work/research}

Further papers are planned based on this project that will focus on the teachers' perspectives of involvement and the skills and capabilities that were developed as a result, and further discussion of the student aspects, including changes in engagement levels with various aspects of the course. Engagement with all 12 modules will also be further investigated including completion rates for the Xero Advisor certificate. As alluded to earlier, further longitudinal studies would be required to see if the noted improvement in overall performance has continued. 
Further data is required to confirm whether this overall shift in the overall performance has continued. As a team we are also considering integration of Xero in later courses and will then be able to track students' skill development. All such research will ensure ethical use of student data and information. Comparative studies with other universities who have implemented Xero would also be a worthwhile endeavour. Other studies could be conducted to investigate aspects such as qualitative data including student emails and feedback from teaching staff, student responses to feedback surveys and student interaction data with the Learning Management System (LMS).

\section{Implications for Educational Technology Integration}

This experience has demonstrated to the teaching team that it is important to incorporate transferable skill development to enhance the student learning experience and ensure that students develop understanding of how and why this knowledge and skill transferability is important. Similarly, this experience has highlighted that it is not sufficient to just teach how to use the specific software, students need to be provided with opportunities for practice, and provided additional support. Identifying obstacles and clarifying ambiguities allowed students to understand the principles and concepts that underlie the software. This enabled students to engage in problem solving, as they were then more likely to identify where, how, and why transactional errors may have occurred and more readily able to amend accordingly. Through the development of different terminology use (accounting and non-accounting), students were assisted in developing these skills and knowledge. Alongside the content and technical knowledge, staff also need to develop capabilities in all aspects of LA, from determining appropriate data, analysing and interpreting that data and implementing appropriate actions as a result of interpretation of the analysis.

\section{Acknowledgement}

We acknowledge the support provided for this project, and particularly the development of the support videos, through the USQ 2019 Grants for Embedded Learning and Teaching Strategy.

\section{References}

ACCA. (2016). Professional accountants - the future: Drivers of change and future skills. https://www.accaglobal.com/an/en/technical-activities/technical-resources-search/2016/june/professionalaccountants-the-future-report.htm.html

Alshurafat, H., Beattie, C., Jones, G., \& Sands, J. (2020). Perceptions of the usefulness of various teaching methods in forensic accounting education. Accounting Education, 29(2), 177-204. https://doi.org/10.1080/09639284.2020.1719425

Bakharia, A., Corrin, L., de Barba, P., Kennedy, G., Gasevic, D., Mulder, R., Williams, D., Dawson, S., \& Lockyer, L. (2016, April 25-29). A conceptual framework linking learning design with learning analytics LAK '16: Proceedings of the Sixth International Conference on Learning Analytics \& Knowledge, Edinburgh Scotland. https://doi.org/10.1145/2883851.2883944

D'Aquila, J. M., Wang, D., \& Mattia, A. (2019). Are instructor generated YouTube videos effective in accounting classes? A study of student performance, engagement, motivation, and perception. Journal of Accounting Education, 47, 63-74. https://doi.org/10.1016/j.jaccedu.2019.02.002

Dyckhoff, A. L., Zielke, D., Chatti, M. A., \& Schroeder, R. (2011). eLAT: An Exploratory Learning Analytics Tool for Reflection and Iterative Improvement of Technology Enhanced Learning EDM 2011 4th International Conference on Educational Data Mining, Eindhoven, Netherlands. http://citeseerx.ist.psu.edu/viewdoc/download?doi=10.1.1.1032.3892\&rep=rep1\&type=pdf\#page=367

Forbes, H., Opresc, u. I., Downer, T., Phillips, N. M., McTier, L., Lord, B., Barr, N., Alla, K., Bright, P., Dayton, J., Simbag, V., \& Visser, I. (2016). Use of videos to support teaching and learning of clinical skills in nursing education: A review. Nurse Education Today, 42, 53-56. https://doi.org/10.1016/j.nedt.2016.04.010

Greller, W., \& Drachsler, H. (2012). Translating learning into numbers: A generic framework for learning analytics. Journal of Educational Technology \& Society, 15(3), 42-57. https://www.jstor.org/stable/pdf/jeductechsoci.15.3.42.pdf

Groccia, J. E. (2018). What is student engagement? New Directions for teaching and Learning, Summer 2018(154), 11-20. https://doi.org/10.1002/t1.20287

Gunn, C., McDonald, J., Donald, C., Milne, J., \& Blumenstein, M. (2017). Building an evidence base for teaching and learning design using learning analytics. AkoAotearoa. https://ako.ac.nz/assets/Knowledge- 
centre/NPF-15-008-Building-an-Evidence-Base-for-Teaching-and-Learning-Design-Using-LearningAnalytics-Data/RESEARCH-REPORT-Building-an-evidence-base-for-teaching-and-learning-design-usinglearning-analytics.pdf

Jones, H. (2015). The 'I's have it: Development of a framework for implementing learning analytics. 32nd Australasian Society for Computers in Learning in Tertiary Education Conference: Globally Connected, Digitally Enabled (ASCILITE 2015), Perth, Australia. http://www.2015conference.ascilite.org/wpcontent/uploads/2015/11/ascilite-2015-proceedings.pdf

Kuh, G. D. (2009). What student affairs professionals need to know about student engagement. Journal of College Student Development, 50(6), 683-706. https://doi.org/10.1353/csd.0.0099

LAK11. (2011). 1st International Conference on Learning Analytics \& Knowledge. https://tekri.athabascau.ca/analytics/

Lockyer, L., Heathcote, E., \& Dawson, S. (2013). Informing pedagogical action: Aligning learning analytics with learning design. American Behavioral Scientist, 57(10), 1439-1459. https://doi.org/10.1177/0002764213479367

Lyon, J. (2020). Future ready: Accountancy careers in the 2020s. https://www.accaglobal.com/us/en/professional-insights/pro-accountants-thefuture/future ready 2020s.html

Machera, R. P., \& Machera, P. C. (2017). Computerised accounting software; A curriculum that enhances an accounting programme. Universal Journal of Educational Research, 5(3), 372-385. https://doi.org/10.13189/ujer.2017.050310

Morris, T. H. (2020). Experiential learning - a systematic review and revision of Kolb's model. Interactive Learning Environments, 28(8), 1064-1077. https://doi.org/10.1080/10494820.2019.1570279

Siemens, G. (2013). Learning analytics: The emergence of a discipline. American Behavioral Scientist, 57(10), 1380-1400. https://doi.org/10.1177/0002764213498851

Viviers, H. A., \& de Villiers, R. (2020). Teaching methodology in accounting education. In J. Fouché \& N. VanderMerwe (Eds.), South African Accounting Education Stocktake (pp. 27-56). African Sun Media. https://doi.org/10.18820/9781928480471/02

Wells, P. K. (2018). How well do our introductory accounting text books reflect current accounting practice? Journal of Accounting Education, 42, 40-48. https://doi.org/10.1016/j.jaccedu.2017.12.003

Jones, G, Jones, H, Pensiero, D \& Beattie, C. (2021). Enhancing students' employability skills and experiential learning through integration of Xero software. In Gregory, S., Warburton, S., \& Schier, M. (Eds.), Back to the Future - ASCILITE '21. Proceedings ASCILITE 2021 in Armidale (pp. 121-130).

https://doi.org/10.14742/ascilite2021.0116

Note: All published papers are refereed, having undergone a double-blind peer-review process.

The author(s) assign a Creative Commons by attribution licence enabling others to distribute, remix, tweak, and build upon their work, even commercially, as long as credit is given to the author(s) for the original creation.

(C) Jones, G, Jones, H, Pensiero, D \& Beattie, C. 2021 